\title{
Employers' views of the impact of mental health problems on the ability to work
}

\author{
Inger Jansson ${ }^{\mathrm{a}, \mathrm{b}, *}$ and A. Birgitta Gunnarsson ${ }^{\mathrm{c}, \mathrm{d}}$ \\ ${ }^{a}$ Department of Rehabilitation, School of Health and Welfare, Jönköping University, Jönköping, Sweden \\ ${ }^{\mathrm{b}}$ Nyckeln Competence Centre for Pedagogics in Healthcare, Kalmar County Hospital, Kalmar, Sweden \\ ${ }^{\mathrm{c} D e p a r t m e n t ~ o f ~ R e s e a r c h ~ a n d ~ D e v e l o p m e n t, ~ R e g i o n ~ K r o n o b e r g, ~ V a ̈ x j o ̈, ~ S w e d e n ~}$ \\ ${ }^{\mathrm{d}}$ Department of Clinical Neuroscience and Rehabilitation, Sahlgrenska Academy at University \\ of Gothenburg, Sweden
}

Received 25 January 2017

Accepted 6 July 2017

\begin{abstract}
.
BACKGROUND: Mental health problems (MHP) are common in working life and can be hard to respond to for employers. Therefore, knowledge of employers' perceptions of employees with MHP is important to support coping efforts of persons and their work environments.

OBJECTIVE: Identify and characterise employers' perceptions of the impact of MHP on work ability.

METHODS: Twelve employers with experience of employees with MHP were interviewed. Data were analysed with a phenomenographic method.

RESULTS: The first main category, "Experiences of employees with MHP", included experiences of diffuse and unexpressed signs of the onset of MHP and frustration among employers and work-mates which was difficult to verbalise. MHP could also be turned off, thus having no impact on work ability. The second main category, "Strategies to handle effects of MHP in the workplace", included the importance of continual responsiveness and communication, and of fluctuating adaptations. The informants expressed diversity in the workplace as a strategy.

CONCLUSIONS: Employers have experiences of, as well as strategies for, how to handle MHP at times when they impact with the ability to work. However, neither experiences nor strategies were explicitly pronounced and verbalised which makes it a challenge to develop strategies and guidelines in workplaces.
\end{abstract}

Keywords: Interviews, mental health, phenomenography, workability, workforce

\section{Introduction}

\subsection{Working life and mental health problems}

Working life is an arena where people spend a great part of their lives. People are expected to contribute

\footnotetext{
*Address for correspondence: Inger Jansson, Department of Rehabilitation, School of Health Sciences, Jönköping University, Box 1026, SE-551 11 Jönköping, Sweden. Tel.: +46 36101311; E-mail: inger.jansson@ju.se.
}

to society by being self-supportive and productive. However, the ability to be self-supportive and productive can decline due to mental health problems (MHP). MHP are common in working life [1] and can have an impact on the individual's ability to be productive. MHP may also affect workplaces, and in the long run most workplaces are affected $[1,2]$.

MHP are the most common cause of sick leave in most Western countries [3]. In Sweden, which is the focus for this study, about $90 \%$ of all sick listing 
for MHP is due to common mental disorders (CMD), i.e. anxiety, depression and stress disorders [2]. Sick leave patterns for CMD vary over time and according to regulations. MHP also include severe mental disorders (SMD), like schizophrenia and bipolar disorders. Sick leave for SMD shows a more stable pattern than sick leave for CMD [4, 5]. Besides, neuropsychiatric disorders like attention deficit hyperactivity disorders (ADHD) and attention deficit disorders (ADD) are also included within MHP and are an increasing contributor to the costs for sick leave and health care $[6,7]$.

\subsection{MHP from the perspective of the individual}

From the perspective of the individual, MHP are a risk both for long-term sick leave as well as for exclusion from working life. Exclusion from working life can lead to a restricted economic situation [1]. MHP also involve individual suffering which may have an influence on the individual's family members and other relations [1]. The risk of onset of MHP is most common in working age, especially between 30 and 49 years [8]. For many people in the Western countries, this corresponds with the life period when they are establishing themselves in working life and developing a worker role. Thus, MHP have a huge impact and consequence on the individual's possibilities to earn their living [1, 8]. Being on longterm sick leave thus has economic consequences as well as consequences on social networks, self-esteem and self-efficacy [1,2]. The distribution of MHP can vary among different groups in different societies [1, 9] although there are major gaps in the knowledge in this area, for example, about the situation in the developing world [9]. However, MHP affect women to a larger extent than men in Sweden [8] as well as in other Western countries [1]. CMD occur almost twice as much among women than among men $[1,8]$. There is a higher prevalence of substance use among men with MHP than among women, both in Sweden [4] and internationally [9]. Migrants and ethnic minorities show higher prevalence for MHP internationally [1]. Immigrants with experiences of war are more afflicted of post-traumatic stress disorders than persons born in Sweden [4].

\subsection{MHP from the perspective of health care}

In health care, extended mental ill health has led to an increase in passive sick listing, e.g. a period of paid sick leave from work, often together with drug treatment without any active treatments enhancing the individual's own efforts for recovery [10, 11]. Measures have been undertaken to develop other methods with the aim of reducing sick listing and promoting a return to work, in Sweden [12] as well as internationally [13-15]. These measures, mainly cognitive behavioural therapy (CBT), have usually been undertaken in health care contexts without the involvement of the workplace [12-15], albeit other forms of support targeting the workplace rather than the individual solely, are occurring both within and outside the medical context such as Individual Placement and Support [16], Supported Employment [17] and guidelines for employers [18, 19].

Methods for treating CMD, like CBT, and with evidence for reducing symptoms have been transferred to the purpose of reducing sick leave as well as promoting a return to work. However, studies have shown that there is no or limited evidence for reduced sick leave and increased return to work $[12,14]$. The methods seem to have an impact on a functional level, i.e. they reduce symptoms but have less impact on an activity level, i.e. to promote return to work [10, 12-15, 20, 21]. Studies have also shown that health care professionals lack knowledge of circumstances in workplaces and are therefore uncertain about demands and expectations in the work situation. This is especially problematic when dealing with symptoms with general effects, like fatigue, stress and anxiety $[22,23]$.

\subsection{MHP from the perspective of employers}

Employers are not only responsible for planning and organising work. They are also obliged to provide a healthful workplace [24]. However, from the perspective of employers, MHP are not only a health problem but also a productivity problem $[25,26]$. MHP may lead to both productivity loss and loss of human resources. Productivity loss may occur in the case of both presenteeism and absenteeism. In the case of presenteeism, the employee is at work but has reduced ability to work and to be productive [27]. For example, depression disorders alone have been estimated to be the most costly disorders in terms of presenteeism in the United States [25]. Absenteeism due to MHP implies increased costs for the employer, in terms of increased sick leave costs, costs for productivity loss and costs for substitutes and re-recruitments [25]. 
MHP with an impact on work performance lead to a loss of human resources. Work duties that could previously be conducted without problems are now performed in a less effective way, thus having a negative impact on productivity. Work-related MHP are more common among individuals who have jobs with high demands and low social support and in jobs with human contacts, so-called 'contact jobs' [28]. Despite the frequent occurrence of MHP in working life, there is a widespread uncertainty among employers about how to handle and meet the needs of employees with MHP [2, 29]. The lack of knowledge about how to deal with MHP in the workplace has led to unnecessary work absenteeism and productivity losses $[1,25]$.

Sick leave and work absenteeism due to MHP present a public health challenge in Western countries $[1,30]$. For many, MHP in working life are experienced as being hard to cope with, for the individual, health care professionals and employers [31].

\subsection{Mental health and work ability}

The ability to work is mostly related to individual health-related issues [32, 33] However, ability to work can be reduced as well as enhanced by a range of reasons and circumstances both outside and within the workplace. In a study [33], which preceded this study and was conducted with the same employers as this study, employers' perceptions of work ability were described. Employers expressed not only health problems but also other circumstances in the individual's private life, like divorce or building a house, as diminishing the ability to work. Also, difficulties adapting to norms were perceived as restricting work ability. This indicates a broader perspective than purely health-related issues that can have an impact on work ability from the viewpoint of employers, which has also been found in other studies [34]. Knowledge of employers' experiences of the impact of MHP on the ability to work is restricted, mainly since MHP are still an invisible and silent phenomenon in working life [27]. Employers' knowledge and views of employees with MHP are important and can contribute to a better understanding and developing strategies to enable people with MHP to take part in working life. Therefore, the aim of this study was to identify and characterise employers' experiences and perceptions of the impact of MHP on work ability. It was anticipated that results would facilitate development of strategies to enhance work ability.

\section{Method}

\subsection{Study design}

This study had a qualitative design based on a phenomenographic approach [35] in which the purpose is to focus on human experiences of a phenomenon. When using phenomenography, the intention is not to reveal a common specific core of a phenomenon, but rather to describe a variation of perceptions and interpretations of reality $[35,36]$.

\subsection{Informants}

The presumptive informants were chosen purposefully, aiming to obtain a variety of perceptions and from various job branches. Inclusion criteria were employers responsible for hiring employees, with knowledge of work demands and experience of employees with MHP.

\subsection{Procedure and data collection}

The first author (IJ) contacted employers, i.e. presumptive informants, first by telephone. When the inclusion criteria were met, they were sent written information by e-mail and were asked to participate. In order to obtain a variation of statements from the informants, which is the intention of phenomenographic research [36], there was a desire to include employers from different sizes of companies and types of production, as well as different requirements placed on employees in terms of demands regarding education and skills. Furthermore, the desire was to reach a diverse range of employers with respect to gender, age and years of experience as an employer.

The data collection, which was performed by the first author (IJ), involved individual interviews. Data were collected from December 2012 to March 2013. After informed verbal consent the interview was conducted and each informant was interviewed once. The interviews lasted between 30 and 90 minutes. Ten of the interviews were performed at the employers' workplaces, and two of them were performed by telephone. All interviews were audiotaped, with the permission of the employers, and then transcribed verbatim. 
The interviews were formed as semi-structured and open-ended dialogues, in line with phenomenographic research [36], and the informants were encouraged to choose aspects of the phenomenon he or she wanted to elaborate on. Firstly, opening questions regarding the workplace and production were asked. Then the informants, i.e. the employers, were encouraged to describe their perceptions of the impact on work ability when employees experience symptoms of MHP. The interviews started with "Please tell me about your perceptions and experiences from the impact of MHP on ability to work", followed by follow-up questions, such as "Can you please describe/explain that further?" Follow-up questions lasted until the interviewer was satisfied that she and the informant had reached a state of mutual understanding, in line with Stenfors-Hayes et al. [36].

\subsection{Data analysis}

A phenomengraphic method [37] was used for the data analysis. The various steps of the analysis were carried out as an iterative process by the two authors (IJ, ABG). Data were processed as one dataset, focusing on differences and similarities regarding the phenomenon, i.e. the impact on work ability when experiencing symptoms of MHP. All seven steps proposed by Dahlgren and Fallsberg [37] were used. In the first step, familiarisation, the data were listened to and read through. Then, in the second step, condensation, the data were condensed with regard to the aim of the study. In the third step, comparison, the various statements were compared with each other in order to identify differences and similarities. In the fourth step, grouping, the statements were grouped together into categories. The fifth step, labelling, involved finding semantic expressions for the categories. In the sixth step, contrasting, the various categories were compared concerning similarities and differences. Finally, in the seventh step, logical relationship, relationships between the categories and their statements in the form of various dimensions of the phenomenon were exposed. In order to enhance trustworthiness [36], the researchers have discussed problems and phenomena throughout the research process and have considered their pre-understanding. Throughout the interviews, the interviewer asked for clarifications and confirmation, as a form of member checking. The first author (IJ) has knowledge of interviewing, and has extensive experience of working with vocational rehabilitation. She has a genuine interest in the phenomenon, which according to Stenfors-Hayes et al. [36] is of importance in phenomenographic research. The second author (ABG) has experience of research in the mental health field, as well as extensive experience of working in the mental health care field. Both authors (IJ, ABG) also have experience of qualitative research.

\subsection{Ethical considerations}

The study was performed in accordance with the Swedish Act concerning the Ethical Review of Research Involving Humans [38]. All participants provided informed verbally consent. The participants were employers and not in a position of dependence to the researchers. However, they were informed about the study, and were assured that all data would be stored securely, analysed on a group level and treated confidentially, i.e. no information regarding employees, employers or workplaces would be identifiable.

\section{Results}

Twelve employers, six men and six women, from twelve workplaces in the south of Sweden took part in the study. All employers had experiences of employees with MHP. The informants' mean age was 50 years (36-65 years) and they had worked as employers for between 2 and 25 years. Two of the workplaces had higher educational requirements for employees and five of them had lower educational requirements, while five had more mixed educational requirements. Among the workplaces, five had mixed personnel regarding gender, three had mostly male employees and four had mainly female employees. The types of production varied, e.g. manufacturing, transportation, education, social work, accommodation activities, and information and communication. The workplaces therefore represented various branches of industries, thus implying various demands on employees (see Table 1).

From the results of the interviews, two main categories - Experiences of employees with MHP and Strategies to handle effects of MHP in the workplace - could be identified. Each of these main categories was composed of three categories (Table 2).

\subsection{Experiences of employees with $M H P$}

The main category Experiences of employees with $M H P$ emanated in three categories: 'Diffuse and 
unexpressed signs', 'Frustration among employers and work-mates' and 'No impact on work ability'.

\subsubsection{Diffuse and unexpressed signs}

MHP were perceived as intangible and were seldom explicitly pronounced, a fact that the informants expressed they had difficulties interpreting. The informants expressed difficulties putting into words and verbalise this worrying change in the employee. This intangible appearance of a change was, according to the informants, difficult to handle and cope with for both employers and co-workers. Diffuse and unexpressed signs of MHP might be manifested in short-term sick leave, reduced ability to focus or difficulties adapting to changes.

3.1.1.1. Short-term sick leave. In retrospect, the problems could be perceived as being manifested in short-term sick leave mainly for physical problems, e.g. headache or stomach ache. The connection between short-term sick leave and symptoms of MHP were not revealed immediately but could be traced afterwards.

Table 1

Characteristics of the informants $[n=12]$ and the workplaces

\begin{tabular}{lc}
\hline Characteristic & \\
\hline Gender [men/women] & $6 / 6$ \\
Mean age [min-max] & 50 [36-65] \\
Main branch of industry* & \\
$\quad$ Agriculture, forestry and fishing & 1 \\
Manufacturing & 3 \\
Construction & 2 \\
Wholesale and retail trade & 3 \\
Education & 1 \\
Administrative and support service activities & 1 \\
Information and communication & 1 \\
\hline
\end{tabular}

*Branches of industry according to Swedish Standard Industrial Classification.
"Well, sometimes you don't see before... suddenly one day when the person doesn't come... sometimes you can be hind-sighted and check how [their] sick leave looks and you'll see, well... there are quite a lot of days here..." (Informant 3)

The underlying reasons for these short-term sick leave periods could be explicitly expressed and revealed in rehabilitation dialogues, i.e. situations when the employer and the employee arrange a meeting with a focus on the employee's work situation.

3.1.1.2. Reduced ability to focus. The perceptions of commencing MHP were that employees who used to be alert and focused underwent a change and became mentally absent. When this happened, the employee appeared pre-occupied and did not seem like the person he or she used to be. This altered appearance could be perceived as a limited self-reflection from the view of the employers. The employee was pre-occupied with himself/herself and appeared to have difficulties focusing on work duties and other employees. Reduced ability to focus, i.e. being attendant on work duties, reduced the ability to work. The reduced ability to focus had an impact on handling and planning work duties, which sometimes led to unexpected errors occurring.

“Then suddenly, it doesn't work as well as it used to, because the person starts to make errors, you know simple errors, guess it's a lack of concentration..." (Informant 6)

\subsubsection{Difficulties adapting to changes were} expressed as strong and emotional reactions such as crying, getting upset or getting angry. The emotional

Table 2

Main categories and categories of employers' perceptions of employees with mental health problems (MHP)

\begin{tabular}{ll}
\hline Experiences of employees with MHP & Strategies to handle effects of MHP in the workplace \\
\hline Diffuse and unexpressed signs & Be responsive and communicate \\
Short-term sick leave & Daily monitoring \\
Reduced ability to focus & Pay attention to divergences \\
Difficulties adapting to changes & Organising scheduled dialogues \\
\hline Frustration in the workplace & Adapt and enable \\
Employers' frustration & Employees' tendencies towards adaptation \\
Work-mates' frustration & Employers' tendencies towards adaptation \\
Language for MHP & Modify work duties \\
\hline No impact on work ability & Diversity in the workplace \\
Ability to turn off & Advantages and risks with diversity \\
Ability to use time & Employers as models \\
& Fine, but not in my backyard \\
\hline
\end{tabular}


reactions were often perceived as unexpected. These strong reactions to adapt to changes demanded by superiors could appear in a concrete work situation as well as in relating to work-mates or to the employer. Changes that could be part of ordinary working circumstances seemed to be insurmountable for an employee with commencing MHP. They could react strongly and unexpectedly to even minor changes that other employees regarded as part of ordinary working circumstances. These strong reactions from employees in their difficulties adapting to changes could appear puzzling to both managers and work-mates.

"The other five in the department said, well $O K$ now we have new directions again and then you read them and follow them but this person then, she starts to cry... new direction. . . and that makes it a huge problem." (Informant 12)

\subsubsection{Frustration in the workplace}

MHP seldom commenced in an explicit and clear way. The diffuse and unexpressed signs were perceived as disturbing, regarding both the employee's work performance and his or her communication with managers and co-workers, and sometimes with customers. This meant that manifestations of MHP were difficult to identify which could evoke frustration. Employers' frustration as well as work-mates' frustration could be articulated as feelings of insecurity together with irritation and with difficulties verbalising their experiences.

3.1.2.1. Employers' frustration. Feelings of frustration, e.g. irritation and disappointment, could according to the informants - be evoked among the employers when an employee had signs of MHP which interfered with the ability to work. For example, when an employee did not perform tasks according to predetermined rules, the unusual, unexpected and sometimes odd performance could evoke frustration. Knowing about the employees' problems made it easier for the informants as employers not only to cope with the problems but also to understand the employee's situation. "He doesn't do it because he wants to annoy me, but sometimes his ability to focus is not enough, it gets too monotonous." (Informant 11) When the informants understood the reason and the dilemma for an employee, it was easier to find a solution. This solution could generally be easy to arrange. "I have discovered, I have to give him various tasks during the day, otherwise it gets too boring." (Informant 5)
3.1.2.2. Work-mates' frustration. According to the informants, work-mates could sometimes have more or less knowledge of the employee's problems. However, mostly they did not know. The effects of an employee's MHP could also evoke frustration among his or her work-mates. Work-mates could start to complain and express dissatisfaction with a fellow work-mate. However, the informants experienced that work-mates often did not want to complain, hesitating to bring the problems to the surface. Often the problems in relation to a work-mate experiencing MHP were only raised when the situation became unsustainable. The informants showed awareness of the power of work-mates to either support or suppress a work-mate. The work-mates' frustration could lead to an irritated attitude towards the person with problems. "To not say hello or to say mean things...It's easy to break even the strongest fairly quickly." (Informant 3)

3.1.2.3. Language for MHP. The informants mainly expressed MHP that they had encountered using generic descriptions. The knowledge of an employee's MHP was rather understood as a consequence of the employee's sick leave or contact with health care. Since they had been on sick leave and/or had contact with health care they had some form of MHP, however they were still not explicitly pronounced. Often the problems were described as "something with the nerves" (Informant 11), "feeling low" (Informant 12), "stressed" (Informant 3) or "absent" (Informant 5). The problems could also be described as manifestations, such as "hyperventilating breathing" (Informant 2) or "starting to cry" (Informant 10). Sometimes the MHP were expressed using the name of the diagnosis. For example, the term 'ADHD' was applied, as well as 'bi-polar' and 'burn-out'. However, these descriptions were exceptions rather than the rule.

\subsubsection{No impact on work ability}

Experiences of employees with MHP without any impact on ability to work were also expressed. The informants' perceptions were that employees with MHP could have the ability to turn off their problems as well as the ability to use time.

3.1.3.1. Ability to turn off. There were also experiences of employees with MHP who had the ability to turn off problems and regard the workplace as a liberated zone. The experiences among the informants were that these employees found it important to 
have a job and to engage in something outside themselves. The informants perceived that work gave the employees an opportunity to leave their problems for a while and distract themselves from their MHP. In other words, going to work and doing something productive together with others could create a feeling of relief.

"I know she has huge problems, but here, she doesn't talk about them, except for some occasions when her problems were too huge so she couldn't turn them off, but usually she is on the job, here and now, and does what she is supposed to do." (Informant 2)

3.1.3.2. Ability to use time. Given the right conditions, employees with MHP were found to produce as much, and even more, than the average employee. There were perceptions among the informants that employees with MHP used their time in a more efficient way. They could be more focused on work duties and did not split their attention. They did not start chatting when they were occupied in a duty. These employees were also perceived as less apt to take prolonged coffee breaks, which could be expressed as "I think they use their time a bit differently... They are more oriented towards the task." (Informant 1)

\subsection{Strategies to handle effects of MHP in the workplace}

The main category Strategies to handle effects of $M H P$ in the workplace included three categories: 'Be responsive and communicate', 'Adapt and enable' and 'Utilise diversity'.

\subsubsection{Be responsive and communicate}

Daily monitoring, paying attention to divergences and organising scheduled dialogues were highlighted as strategies for being responsive and communicating with an open-minded dialogue with employees.

3.2.1.1. Daily monitoring was expressed as a strategy for an employer that was useful when multiple employees have MHP. However, the informants stressed the importance of being responsive and being attentive to the emotional atmosphere among all employees, not only those with MHP. Ordinary chats, sometimes stopping for just a few minutes and exchanging ordinary daily experiences in a gentle way, was one way of checking the emotional atmosphere. This could be expressed as "And we exchange a few words, how was it today, how does that feel, just this short check off gives indications..." (Informant 3)

3.2.1.2. Paying attention to divergences and being observant was expressed as a strategy to discover MHP among employees and bring them to the surface, thus making them manageable. The divergences could be reported from other employees or observed by the employers. The divergences could range from minor discrepancies like not taking a lunch break as usual to unexpected errors occurring in the work situation, which could be expressed as "He seemed apathetic...so I asked him, what's the problem, something at work?" (Informant 7)

\subsubsection{Organising scheduled dialogues was} another strategy used. This strategy was organised in a planned way, like regular dialogues about health and wellness, as well as dialogues about the employee's performance at work. In some workplaces, these dialogues were performed at least once a year. Other workplaces had explicit rule-governed dialogues and were carried out after fixed days on short-term sick leave. "We check those who are on sick leave. We have these feel-good conversations where we check those who have been on sick leave, so we can support them." (Informant 8)

\subsubsection{Adapt and enable}

The informants expressed various aspects of adapting and enabling. Adapting strategies could be initiated by the employee as well as by the employer. The informants also expressed various possibilities to modify work duties for an individual employee.

\subsubsection{Employees' tendencies towards adaption.}

According to the informants, the employees' own tendencies to handle their work situation in relation to their MHP were of great importance. The individual's way of coping with demands and challenges at work was emphasised. The experience was that some employees had difficulties finding their own strategies, while other employees had the capacity to adapt to the work situation.

"She came to me and said, today I've had so much to do and I can't stand it, I have to cry. And she cried for a while and went home earlier that day. Next day she was back, feeling alright." (Informant 2) 
Although work duties were expected to be performed following various safety and quality rules, the employee's performance could still be adapted in relation to individual needs. For example, the informants expressed the employee's possibility to close the door and slow down instead of spinning off in a stress reaction. Another strategy that the informants expressed as being constructive was the employee's elaboration of his or her own structure for performing the job.

\subsubsection{Employers' tendencies towards adaptation.} If the employee was hired and his or her MHP were known from the beginning at the workplace, it was expressed as a purposeful intention to adapt as far as possible for the individual. This intention could almost be expressed as a challenging competition: "I, myself, have decided to hire them, so I have to take the challenge." (Informant 1)

The informants described how they as employers had the possibility to balance demands on the employee. They described how they could switch between challenging the employee, giving positive feedback, encouraging, creating comfort and evoking interest regarding work tasks. An employee who had grown from passivity and insecurity to acting like a professional, i.e. he or she performs a good job, could fill the informants with a sense of pride. They described how they used experienced work-mates as mentors. According to the informants, these workmates were also filled with a sense of pride when they had been involved in bringing someone "back on track" (Informant 3). For other informants, the attitude to adaptation was less positive. The work duties were organised with the purpose that all employees should be able to do the same duties. A change in that organisation would affect the other employees' work duties, and therefore employers rejected the idea of adapting for an individual employee.

3.2.2.3. Modify work duties. Some of the informants said that, as employers, they could arrange and reorganise work duties so that they would suit an employee with MHP better. This way of reorganisation was more common among informants with a close connection to production. These informants used their positions as managers to adapt for longer periods as well as just for the moment. The adaptations mostly concerned stressful parts of the job or duties with high demands on flexibility and self-management. Some informants described how they devised well-structured, predictable work duties for employees with high sensitivity to stress. Other adaptations could be almost the opposite, i.e. to give the individual the freedom to frame his or her way of performing the duties. These adaptions were found to be successful among some of the employees "Usually an e-mail, I can't come to work today... Then I know, he needs to work at home. So, I send some work to him that I know he can manage." (Informant 9). Other ways of adapting work duties were to form complementing work groups. Sometimes the informants searched for help outside the workplace when trying to adapt for the employee. This help from outside could include occupational health care professionals if the problems could be regarded as work-related. Otherwise, help could mean contact with a psychologist, or other professionals offering various forms of psychological therapy.

\subsubsection{Diversity in the workplace}

The informants expressed that they sought diversity among their employees. However, all employees had to adapt to common rules and customs, adopted at the workplace. In general, the informants were positive towards hiring people with MHP and could regard them as contributors to diversity. However, risks with hiring them were also raised.

3.2.3.1. Advantages and risks with diversity. The informants were convinced that diversity among the employees would strengthen the dynamic interaction in the work group and have a good effect on productivity. Various abilities could contribute to better productivity. However, having too many employees with MHP in the same workplace was considered to be a risk. Also, it was important to consider the reactions of the other employees. The informants expressed a dilemma when considering hiring a person with MHP. The dilemma could concern economic dilemmas with fears of high sick leave costs as well as doubts concerning the employee's productivity. Other informants expressed a reluctance to hire a person with MHP, not because they were hesitant about the person's ability to work, but rather because they were hesitant about the reactions from the other employees. "From my point of view, I don't think very much, but I think about what my other employees will think." (Informant 10)

3.2.3.2. Employers as models. There were informants who had the experience that employers who were close to production and had everyday contact 
with the employees could serve as models when introducing or encountering an employee with MHP and different behaviour that could be perceived as deviant among co-workers Through serving as a model for the other employees, they could enable co-workers to find a way to communicate and interact with this person. The employer's goals when hiring a person with MHP was to reach the ability to work that they had recognised beyond a different behaviour. "I mean, if he is very efficient, I don't care, I mean, I have to show that I appreciate his competence and not his behaviour." (Informant 1)

3.2.3.3. Fine, but not in my backyard. The informants expressed that more people with MHP ought to get access to the labour market and be part of the workforce. They had the opinion that most workplaces could hire someone with MHP. Several informants expressed that they were convinced that almost all people have an ability to work despite various limitations. "There is no human in the world, I hope, that doesn't have any ability to work." (Informant 9) However, the informants also expressed that far from all people could work and fit in at their own workplace. When talking about former employees with MHP who had not coped with the work, the conclusion was that that person did not fit in at that workplace but could fit in at another workplace with different circumstances.

\section{Discussion}

This study showed that employers have experience of, as well as strategies for, how to handle MHP that impact on their ability to work. MHP can range from CMD appearing occasionally in an individual's life to SMD afflicting a whole life time and several domains of an individual's daily life [1]. MHP affect almost one in two individuals directly during their life time [27]. MHP occur frequently in working life and they can vary in severity, both between individuals and within an individual over time [1]. This implies a fluctuation in the ability to work. The wide range of symptoms and presentations of MHP may have various impacts on a person's ability to work which implies that these problems need to be handled with a variety of strategies rather than in a uniform way. The informants' experiences of MHP were partly perceived diffuse. They used strategies to handle MHP but they were expressed in a generic way.

\subsection{Non-verbal and verbal communication}

The results showed that the informants had perceived their employees' unexpressed signs of MHP non-verbally and found it difficult to express this intangible experience in words.

The informants emphasised the importance of being sensitive to the emotional, non-verbal atmosphere. This need for sensitivity has also been shown in Byron [39], in which employers' sensitivity to nonverbal information has been highlighted as a factor for enhancing job performance. Being more sensitive to non-verbal information may encourage more supportive behaviour and generate more persuasive arguments in relation to employees [39].

The informants expressed experiences of frustration when facing MHP in the workplace, regarding both their own frustration and other work-mates' frustration. These experiences of the phenomenon were described using generic terminology with generic expressions. The feeling of frustration may be a consequence of the intangible, non-verbal expression. The evocation of frustrated feelings has also been reported by Bertilsson et al. [40] from the perspective of employees with MHP who perceived that their reduced ability to work has an impact on the workplace and on work-mates' work situation [40]. This might indicate awareness among employees with MHP of the frustration that can arise among employers and work-mates. However, this awareness of non-verbalised frustration may be an additional burden for an employee with MHP. Here, there may be a great distance between the language code applied in health care settings and the language code applied in workplaces. In health care settings, MHP are verbalised and "allowed", and it is expected that they will be talked about. In workplaces, concealment is a common way to handle MHP [27, 41]. As many as $70 \%$ of all people globally who have MHP do not receive health care [41], which indicates that many people take part in working life while struggling with their MHP alone. Many employees are still reluctant to disclose their MHP in working life [27, 40, 42]. However, there are also experiences of disclosing MHP as an important strategy to get support [40]. In this study, MHP were either known about in advance or revealed to the informants. Concealing MHP may lead to poorer work performance that can be interpreted as poor work ethics [27]. Absenteeism due to concealed MHP may often be interpreted as a lack of job satisfaction or a lack of satisfaction with workmates [27]. According to Bilsker [43] it is important 
to establish closer contact between workplaces and mental health care. Kahn [44] argue that there is a huge difference regarding language, code culture and philosophy in mental health care and workplaces.

\subsection{Cognitive abilities and self-management}

The informants described how they re-organised work duties with demands on self-management and flexibility to better suit the employee with MHP. This adaptation is in line with the expressed experience of diminished self-confidence and reduced cognitive abilities from people with MHP [40].

In working life today, self-management is supposed to be part of the ability to work [34]. Modern working life is also characterised by extended cognitive work duties [45]. Self-management puts demand on cognitive abilities and coping skills, such as planning, organising and prioritising, as well as selfconfidence [27, 34]. MHP can lead to cognitive impairment and delimit cognitive abilities, resulting in reduced work performance, and can have more impact on work tasks with cognitive demands rather than physical demands [27, 46].

\subsection{The ability to turn off}

According to the informants, some employees were capable of turning off and leaving their MHP at home, which may correspond to findings in other studies. For example, Bertilsson et al. [40] found that people with MHP put on a façade or a role to better manage the work situation. However, according to Bertilsson et al. [40], turning off may be energyconsuming and in the long run lead to exhaustion. On the other hand, the focus on work duties may also help to distract oneself and provide a "rest" from MHP. The informants expressed experiences of a more efficient way to use time among employees with MHP, which may be a manifestation of directing focus on the work duties as a distracting manoeuvre. Distraction is a strategy to handle MHP which has been evaluated in various studies, e.g. Pöllänen [47], who explored how crafts provided recreation, satisfaction and optimism among women, and was perceived as helpful in coping with stress. Other studies, e.g. Grape Viding et al. [48], have evaluated the health effects of cultural activities for women experiencing stress-related disorders. Their findings showed positive outcomes regarding burnout symptoms, sense of coherence and self-rated health. The possibility to be able to distract oneself in a work situation as well, might be experienced if the work duties are perceived as meaningful and interesting for the employee. Borg et al. [49] have found that recovery from mental illness may be enhanced when attention is directed towards work duties and doing something for other people.

\subsection{The importance of leadership}

Some of the informants expressed that they used their positions as managers to adapt for the moment as well as for longer periods for employees with MHP. The informants, as employers, were interested in reaching and using the ability to work that people with MHP could have. Some employers seemed more disposed to reach the employees' ability to work that could be noticed behind mental symptoms. In these cases, they used their authority and led and organised the work duties in a very concrete way, which indicates situational as well as supportive leadership [16, 50-52].

The informants expressed the importance of daily monitoring depending on the situation. Situational leadership can change and adapt following the employee's needs [50]. It can be amplified as well as moderated or adapted in other ways with consideration to the actual circumstances at that moment. With its focus on flexibility regarding the specific situation, situational leadership may be particularly apt to support diversity, which may suit the needs of employees with MHP with their fluctuating character [50].

The importance of supportive leadership has been highlighted in many studies [51,52]. Supportive leadership is, from the employee's perspective, perceived as being trusted, being supported emotionally and getting feedback [52]. The informants expressed the importance of paying attention to divergences such as emotional changes and communicating with the employee. They also showed willingness to adapt the situation, e.g. working from home, which may be perceived by the employee as being trusted. For people with MHP, situational leadership as well as supportive leadership could therefore be preferable. The development of guidelines and training programmes for handling MHP in the work place is an area under development [53-55] which can enhance a situational as well as a supportive leadership. Results so far, have shown significant better confidence in taking contact with and communicate with people with MHP after taking part in a training programme [54]. 


\subsection{Methodological discussion}

Trustworthiness in phenomenographic research should, according to Sin [56], be considered in terms of validity, objectivity and reflexivity, reliability, research ethics and the integrity of the researcher, and generalisability. Validity deals with internal consistency in the research process. The authors strengthened the validity following the various stage of the phenomenographic process, as suggested by Dahlgren and Fallsberg [37]. Another way to strengthen the validity was to recruit informants from various job branches, in order to ensure an optimal set of categories. According to Sin [56], the readers may be offered the opportunity to judge the validity of data when the authors give a clear description of the informant characteristics, which in this study is given in Table 1. Further, in order to strengthen the validity [56], the first author (IJ) strived to use an interview strategy in which the informants would be encouraged to reflect on and express their meanings, by using follow-up questions, but without any leading questions. The validity has also been strengthened by offering the given quotations.

Objectivity and reflexivity [56] deals with the engagement and interaction between researcher and informants during the interviews, and in this study all informants were interested in the study aim and wanted to talk about their experiences of employees with MHP. Another aspect of objectivity and reflexivity is the fact that the authors are not unaware of the impact on work ability when experiencing MHP, which in turn may be of importance when interpreting the data. In order to strengthen trustworthiness [56], the authors have declared their pre-conceptions in the Method section, and have strived to be reflexive and discussed upcoming problems and phenomena throughout the analysis. One way to support various perspectives when interpreting the data was that the first author (IJ) had an inside perspective when performing all interviews, and the second author (ABG) had an outside perspective when not interviewing, but also by carefully checking the transcriptions for any allegiance problems, as well as taking part in the process of analysis. A further way to minimise the effects regarding reflexivity and objectivity was to document each stage of the research process [56].

Reliability [56] deals with whether or not the findings of the study could be replicated. In order to strengthen reliability, all interviews were audiotaped and transcribed. Another strategy was to provide an accurate description of the research process. According to Sin [56], the research ethics and the integrity of the researcher are of importance when assessing trustworthiness. Research ethics deals with the authors maintaining the confidentiality of the informants, and not revealing any information that makes employees, employers or workplaces identifiable. Further, research ethics were considered, starting with information regarding the purpose of the study, followed by the informants' informed consent.

Generalisability [56] deals with the extent to which the findings from this study could be translated into other settings. A limitation of the study may be the small sample. However, the purpose of qualitative research is not to generalise, but to describe a variety of perceptions, so that the reader can reflect how the findings may be translated to other contexts. Therefore, one strategy was to achieve a broad description of the findings, so that the reader would find the revealed categories useful in his or her own context.

The collection of the data for this study was performed from December 2012 to March 2013, which means that four years has passed. However, the situation for people with MHP in working life has hardly changed noticeably during this time. Sick leave due to MHP has even increased in Sweden as well as in other Western countries $(57,58]$ and The World Health Organization even predicts MHP to by the year 2030 be among the leading causes of burden of disease in the world [59].

\section{Conclusion}

The results revealed that employers have experiences of, as well as strategies for, how to handle MHP which impact on the ability to work. The informants described experiences of intangible signs of MHP interfering with the ability to work and how the onset of MHP could evoke frustration. The informants also raised experiences of employees' ability to turn off MHP, thus having no impact on the ability to work. The informants described strategies to become aware of and handle MHP. They raised the importance of being constantly responsive and paying attention to divergences. The informants showed various tendencies to modifying work duties for employees with MHP. For some, organising work duties in various ways, for longer periods as well as just for the moment, according to the employees fluctuating ability to work, was part of management. Others expressed reluctance, referring to difficulties 
in changing the organisation. Both advantages and risks were raised regarding diversity in the workplace. Further, the informants said that they could act as models when encountering employees with MHP. Other informants could recognise an ability to work among people with MHP but did not find it suitable in their own workplace.

The findings in this study can contribute to the further development of guidelines and programs for a better understanding of MHP appearance and how to handle them in the workplace.

\section{Conflict of interest}

None to report.

\section{References}

[1] OECD. Sick on the job?: Myths and realities about mental health and work. [Internet]. Paris: OECD Publishing; 2012. [cited 2017 Aug 04]. Available from: http://dx.doi.org/10. 1787/9789264124523-en

[2] FORTE. Psykisk ohälsa, arbetsliv och sjukfrånvaro. [Mental health, work and sick leave] (In Swedish) [Internet]. Forskningsrådet för hälsa, arbetsliv och välfärd [Swedish Research Council for Health, Working Life and Welfare]; 2015. [cited 2017 Aug 6]. Available from: http://forte.se/ publikation/psykisk-ohalsa-arbetsliv-och-sjukfranvaro/

[3] McDaid D, editor. Mental health in workplace settings. Consensus paper. [Internet]. Luxembourg: European Communities; 2008. [cited 2017 Aug 06.] Available from: http://ec.europa.eu/health/ph_determinants/life_style/ment al/docs/consensus_workplace_en.pdf

[4] Stefansson CG. Chapter 5.5: Major public health problems - mental ill-health. Scand J Publ Health. 2006;34(67_suppl): 87-103.

[5] Henderson M, Harvey SB, Overland S, Mykletun A, Hotopf M. Work and common psychiatric disorders. J R Soc Med. 2011;104(5):198-207.

[6] WHO. Mental health and work: Impact, issues and good practice. [Internet]. Geneva: World Health Organization; 2000. [cited 2017 Aug 06]. Available from: http://www. who.int/mental_health/media/en/712.pdf

[7] Statistiska centralbyrån [Statistics Sweden]. Förutsättningar i arbetslivet: En undersökning om diskriminering på arbetsmarknaden och arbetssituationen för personer med funktionsnedsättning. [Conditions in the labour market: A survey on discrimination in the labour market and the work situation for persons with disabilities] (In Swedish) [Internet]. Stockholm: Statistiska centralbyrån (SCB) [Statistics Sweden]; 2013. [Cited 2017 Aug 06]. Available from: https://www.arbetsformedlingen.se/download/18.306228a 513d6386d3d81c92/F\%c3\%b6ruts\%20\%c3\%a4ttningar_i_ arbetslivet1.pdf

[8] Försäkringskassan [The Swedish Social Insurance Agency]. Sjukfrånvaro i psykiska diagnoser. En studie av Sveriges befolkning16-64 år [Sick leave due to mental disorders.
A study based on the Swedish population aged 16-64] (In Swedish) [Internet]. Socialförsäkringsrapport 2014:4; 2014. [Cited 2017 Aug 06]. Available from: http://www.forskas verige.se/wp-content/uploads/Sjukfranvaro-Psykiska-Diag noser-2014.pdf

[9] WHO. Gender and mental health. [Internet]. Geneva: World Health Organization; 2002. [cited 2017 Aug 06]. Available from: http://apps.who.int/iris/bitstream/10665/68884/1/a85 573.pdf

[10] Jansson I, Perseius KI, Gunnarsson AB, Björklund A. Work and everyday activities: Experiences from two interventions addressing people with common mental disorders. Scand J Occup Ther. 2014;21(4):295-304.

[11] Sturesson M, Edlund C, Falkdal AH, Bernspång B. Healthcare encounters and return to work: A qualitative study on sick-listed patients' experiences. Prim Health Care Res Dev. 2014;15(4):464-75.

[12] Brämberg Björk E, Klinga C, Jensen I, Busch H, Bergström G, Brommels M, Hansson J. Implementation of evidencebased rehabilitation for non-specific back pain and common mental health problems: A process evaluation of a nationwide initiative. BMC Health Serv Res. 2015;15(1): $1-11$.

[13] Nieuwenhuijsen K, Faber B, Verbeek JH, NeumeyerGromen A, Hees HL, Verhoeven AC, et al. Interventions to improve return to work in depressed people. Cochrane Database Syst Rev. 2014;12:CD006237.

[14] Arends I, Bruinvels DJ, Rebergen DS, Nieuwenhuijsen K, Madan I, Neumeyer-Gromen A, et al. Interventions to facilitate return to work in adults with adjustment disorders. Cochrane Database Syst Rev. 2012;12:CD006389.

[15] Brouwers EPM, Tiemens BG, Terluin B, Verhaak PFM. Effectiveness of an intervention to reduce sickness absence in patients with emotional distress or minor mental disorders: A randomized controlled effectiveness trial. Gen Hosp Psychiat. 2006; 28(3):223-29.

[16] Fioritti A, Burns T, Hilarion P, van Weeghel J, Cappa C, Sunol R, et al. Individual placement and support in Europe. Psychiatr Rehabil J. 2014;37(2):123.

[17] Corbiere M, Lanctot N. Salient components in supported employment programs: Perspectives from employment specialists and clients. Work. 2011;39(4):427.

[18] Bovopoulos NE, LaMontagne AD, Martin A, Jorm AF. Delivering mental health first aid training in Australian workplaces: Exploring instructors' experiences. Int J Ment Health Pr. 2016;18(2):65-82.

[19] Memish K, Martin A, Bartlett L, Dawkins S, Sanderson K. Workplace mental health: An international review of guidelines. Prev Med. 2017;101:213-22.

[20] Jansson I, Gunnarsson AB, Björklund A, Brudin L, Perseius KI. Problem-based self-care groups versus cognitive behavioural therapy for persons on sick leave due to common mental disorders: A randomised controlled study. J Occup Rehab. 2015;25(1):127-40.

[21] Wadell G, Burton KA, Kendall NAS. Vocational rehabilitation - what works, for whom, and when? [Internet]. TSO Publishing; 2013. [Cited 2017 Aug 06]. Available from: http://www.employabilityinscotland.com/media/301260/vo cational_rehabilitation_what_works_for_whom_and_when_ waddell_burton_and_kendall_2008_pdf

[22] Ståhl C, Svensson T, Petersson G, Ekberg K. Swedish rehabilitation professionals' perspectives on work ability assessments in a changing sickness insurance system. Disabil Rehabil. 2011;33(15/16):1373-82. 
[23] Kiessling A, Arrelöv B. Sickness certification as a complex professional and collaborative activity - a qualitative study. BMC Public Health. 2012;12(1):702-10.

[24] Henshaw JL, Gaffney SH, Madl AK, Paustenbach DJ. The employer's responsibility to maintain a safe and healthful work environment: An historical review of societal expectations and industrial practices. ERRJ. 2007;19(3): 173-92.

[25] Klachefsky M. Hidden costs, productivity losses of mental health diagnoses. Benefits Magazine. 2013;50(2): 34-8.

[26] Henderson C, Williams P, Little K, Thornicroft G. Mental health problems in the workplace: Changes in employers' knowledge, attitudes and practices in England 2006-2010. Br J Psychiat Suppl. 2013;55:70-6.

[27] De Lorenzo MS. Employee mental illness: Managing the hidden epidemic. ERRJ. 2013;25(4):219-38.

[28] SBU. Arbetsmiljöns betydelse for symtom på depression och utmattningssyndrom. [The impact of the work environment on symptoms of depression and burnout] (In Swedish) [Internet]. Stockholm: Swedish Council on Health Technology Assessment (SBU) SBU report no 223; 2014. [Cited 2017 Aug 06]. Available from: http://www.sbu.se/contentas sets/800ad7aecf9146c795d3a89c7a957048/arbetsmiljo_de pression_2014.pdf

[29] Gustafsson J, Peralta JP, Danermark B. The employer's perspective on supported employment for people with disabilities: Successful approaches of supported employment organizations. J Vocat Rehabil. 2013;38(2):99-111.

[30] Cottini E, Lucifora C. Mental health and working conditions in European countries. [Internet]. Bonn: Forschungsinstitut zur Zukunft der Arbeit Institute for the Study of Labor; 2010. IZA DP No. 4717. [Cited 2017 Aug 06]. Available from: http://repec.iza.org/dp4717.pdf

[31] Harvard Medical School of Harvard University. Mental health problems in the workplace. [Internet]. Harvard Health Publications; 2010. Harvard Mental Health Letter. [Cited 2017 Aug 06]. Available from: https://www.health.harvard. edu/newsletter_article/mental-health-problems-in-the-work place

[32] Escorpizo R, Finger $M$, Glässel A, Gradinger F, Lückenkemper M, Cieza A. A systematic review of functioning in vocational rehabilitation using the international classification of functioning, disability and health. J Occup Rehabil. 2011;21(2):134-46.

[33] Jansson I, Björklund A, Perseius KI, Gunnarsson AB. The concept of 'work ability' from the view point of employers. Work. 2015;52(1):153-67.

[34] Tse S. What do employers think about employing people with experience of mental illness in New Zealand workplaces? Work. 2004;23(3):267.

[35] Marton F. Phenomenography - Describing conceptions of the world around us. Instr Sci. 1981;10(2):177-200.

[36] Stenfors-Hayes T, Hult H, Dahlgren MA. A phenomenographic approach to research in medical education. Med Educ. 2013;47(3):261-70.

[37] Dahlgren L, Fallsberg M. Phenomenography as a qualitative approach in social pharmacy research. J Soc Adm Pharm. 1991;8(4):150-56.

[38] SFS 2003:460. Lag (2003:460) om etikprövning av forskning som avser människor. [The act concerning the ethical review of research involving humans] (In Swedish) [Internet]. Stockholm: Utbildningsdepartementet [Ministry of education and research]; 2003. [cited 2017 Aug 06]. Available from: https://www.riksdagen.se/sv/dokument-lagar/do kument/svensk-forfattningssamling/lag-2003460-om-etik provning-av-forskning-som_sfs-2003-460

[39] Byron K. Male and female managers' ability to 'read' emotions: Relationships with supervisor's performance ratings and subordinates' satisfaction ratings. J Occup Organ Psych. 2007;80(4):713-33.

[40] Bertilsson M, Petersson EL, Östlund G, Waern M, Hensing G. Capacity to work while depressed and anxious a phenomenological study. Disabil Rehabil. 2013;35(20): 1705-11.

[41] Hanisch SE, Twomey CD, Szeto ACH, Birner UW, Nowak $\mathrm{D}$, Sabariego C. The effectiveness of interventions targeting the stigma of mental illness at the workplace: A systematic review. BMC Psychiatry. 2016;16:1-11.

[42] Haslam C, Atkinson S, Brown SS, Haslam RA. Anxiety and depression in the workplace: Effects on the individual and organisation (a focus group investigation). J Affect Disord. 2005;88(2):209-15.

[43] Bilsker D. Mental health care and the workplace. Can J Psychiatry. 2006;51(2):61-2.

[44] Kahn JP. Workplace mental health quality: Effective recognition, management, evaluation, treatment and benefits. In: Kahn JP, Langlieb AM, editors. Mental health and productivity in the workplace: A handbook for organizations and clinicians. San Francisco: John Wiley and Sons; 2003, pp. 3-27.

[45] Lysaght R, Shaw L, Almas A, Jogia A, Larmour-Trode S. Towards improved measurement of cognitive and behavioural work demands. Work. 2008;31(1):11-20.

[46] Adler DA, McLaughlin TJ, Rogers WH, Hong C, Lapitsky L, Lerner MS. Job performance deficits due to depression. Am J Psychiat. 2006;163:1569-76.

[47] Pöllänen, SH. Crafts as leisure-based coping: Craft makers' descriptions of their stress-reducing activity. Occup Ther Ment Health. 2015;31:83-100.

[48] Grape Viding C, Osika W, Theorell T, Kowalski J, Hallqvist J, Bojner Horwitz D. "The culture palette" - a randomized intervention study for women with burnout symptoms in Sweden. BJMP. 2015;8(2):a813.

[49] Borg M, Veseth M, Binder PE, Topor A. The role of work in recovery from bipolar disorders. Qual Soc Work. 2013;12(3):323-39.

[50] Doyle K, Hungerford C. Leadership as a personal journey: An indigenous perspective. Issues Ment Health Nurs. 2015;36(5):336-45

[51] Schreuder J, Groothoff J, Jongsma D, Zweeden N, Klink J, Roelen C. Leadership effectiveness: A supervisor's approach to manage return to work. J Occup Rehabil. 2013; 23(3):428-37.

[52] Chullen CL, Dunford BB, Angermeier I, Boss RW, Boss AD. Minimizing deviant behavior in healthcare organizations: The effects of supportive leadership and job design. $\mathrm{J}$ Health Manag. 2010;55(6):381-97.

[53] Kitchener BA, Jorm AF. Mental health first aid training in a workplace setting: A randomized controlled trial. BMC Psychiatry. 2004;4:23.

[54] Jensen KB, Morthorst BR, Vendsborg PB, Hjorthoj CR, Nordentoft $M$. The effect of the mental health first-aid training course offered employees in Denmark: Study protocol for a randomized waitlist-controlled superiority trial mixed with a qualitative study. BMC Psychiatry. 2015;15:80.

[55] Bovopoulos NE, LaMontagne AD, Martin A, Jorm AF. Delivering mental health first aid training in Australian workplaces: Exploring instructors' experiences. Int J Ment Health Pr. 2016;8(2):65-82. 
[56] Sin S. Considerations of quality in phenomenographic research. Int J Qual Methods. 2010;9(4):305-19.

[57] Försäkringskassan. [The Swedish Social Insurance Agency] Socialförsäkringen I siffror. [The social insurance in numbers] (in Swedish) [Internet]. Stockholm: Försäkringskassan [The Swedish Social Insurance Agency]; 2016. [cited 2017 Aug 06]. Available from: https://www.forsakri ngskassan.se/wps/wcm/connect/7409a3e3-ffbd-498d-a35d1f0afceebfad/socialforsakringen_i_siffror_2015.pdf?MOD= AJPERES
[58] OECD. Fit mind, fit job. From evidence to practice in mental health and work. [Internet]. Paris: OECD Publishing; 2015. [cited 2017 Aug 04]. Available from: http://dx.doi.org/10.17 87/9789264228283-en

[59] WHO. Global Burden of Disease 2004. [Internet]. Geneva: World Health Organization; 2008. [cited 2017 Aug 06]. Available from: http://www.who.int/healthinfo/global_burd en_disease/2004_report_update/en/ 